\title{
Biopolymer Doped with Titanium Dioxide Superhydrophobic Photocatalysis as Self-Clean Coating for Lightweight Composite
}

\author{
Anika Zafiah M. Rus, S. R. Mohid, S. Nurulsaidatulsyida, and N. Marsi \\ Sustainable Polymer Engineering, Advanced Manufacturing and Material Center (AMMC), \\ Faculty of Mechanical and Manufacturing Engineering, Universiti Tun Hussein Onn Malaysia, 86400 Batu Pahat, Johor, Malaysia
}

Correspondence should be addressed to Anika Zafiah M. Rus; zafiah@uthm.edu.my

Received 25 March 2013; Revised 24 April 2013; Accepted 24 April 2013

Academic Editor: Belal F. Yousif

Copyright ( 2013 Anika Zafiah M. Rus et al. This is an open access article distributed under the Creative Commons Attribution License, which permits unrestricted use, distribution, and reproduction in any medium, provided the original work is properly cited.

\begin{abstract}
The development of a lightweight composite (LC) based on Portland cement concrete with waste lightweight aggregate (WLA) additive was carried out to improve the sustainability and environmental impact and to offer potential cost savings without sacrificing strength. Treatment of the surface of the LC exposed to environmental attack by coating with biopolymer based on waste cooking oil doped with titanium dioxide photocatalysis (TOP) with superhydrophilic property was found to affect the mechanical properties of the LC in a systematic way. The results of compressive strength showed that the composite achieved the minimum required strength for lightweight construction materials of $17.2 \mathrm{MPa}$. Scratch resistance measurements showed that the highest percentages loading of superhydrophilic particles (up to $2.5 \%$ of biomonomer weight) for LC's surface coating gave the highest scratch resistance while the uncoated sample showed the least resistances. Scanning electron microscope (SEM) pictures revealed the difference between the surface roughness for LC with and without TOP coating. TOP is also formulated to provide self-cleaning LC surfaces based on two principal ways: (1) the development by coating the LC with a photocatalytic superhydrophilic, (2) if such a superhydrophilic is illuminated by light, the grease, dirt, and organic contaminants will be decomposed and can easily be swept away by rain.
\end{abstract}

\section{Introduction}

A large amount of waste lightweight aggregate (WLA) and waste cooking oil has become an environmental issue around the world. One useful application that WLA could find would be in the construction industry. Thus large amounts of WLA could be utilized as bitumen pastes, roofs, floor covers, pavement, ceiling roofs, and so forth. As regards, waste cooking oil can be recycled for biodiesel, paint, bio-bag plastic, pencil cases, containers, and so forth [1]. These approaches would reduce pollution and disposal problems. The concept of sustainable development, currently a very important issue, requires that society as a whole becomes aware of the necessity to make the most of all existing resources, combined with minimizing the creation of residues [2].

In this research, the fabrication of LC by WLA and its surface coating from biopolymer made from waste cooking oil was doped with superhydrophilic photocatalysis materials. LC can also be made cheaper by replacing some of the fine aggregate with WLA. These WLA were produced through a process called continuous shredding, which is necessary to create WLA of particle size small enough to replace an aggregate as fine as sand. Such a type of concrete can be used to reduce the weight by as much as $35 \%$ as compared with the commercial standard concrete roof tile, and it offers a reduction in production cost while maintaining the mechanical strength.

A surface coating, known as TOP, was used and prepared based on biopolymer derived from waste cooking oil [3-5] doped with superhydrophilic metal oxide filler. The fabrication method for LC surfaces with or without fillers was formulated and the coating applied onto the surfaces. Physical and mechanical testing was conducted to observe the self-cleaning property of the additive in order to improve its quality as desired. In order for any further study or uptake of this new material to be successful, it is necessary to prepare them not just with the correct properties but also to determine their stability towards degradation from sunlight 
and night humidity. This research is to establish a family of concrete mixes of WLA with Portland cement to produce LC with prescribed properties such as reducing cost and weight while maintaining the mechanical strength.

For example, investigation on the failure of rubberized concrete under flexural loading exhibited a ductile mode as compared to that of nonrubberized concrete. The RA concrete specimens could withstand larger deflection, indicating that they could absorb more energy [6]. This is largely due to the ability of RA to undergo a large deformation before failure. The replacement of natural aggregate with rubber particles resulted in a significant increase of flexural strength and tensile strain of concrete as well as better damping capacity. The addition of rubber particles is effective for reduction of concrete modulus of elasticity and increasing deformability of concrete. The tires rubber waste additives have great influence on concrete deformability after loading was reported $[7,8]$. The strains of the concrete investigated with tires rubber in the beginning of stress increasing are higher as compared to the concrete without rubber waste [9].

The surface coating of LC surfaces by TOP was examined to observe the role of additives as self-clean upon exposure to sunlight and humidity and mechanical properties such as morphology of fracture surfaces by scanning electron microscopy (SEM), water droplet test, and scratch resistance by pencil test for coated and uncoated surface to assess its stability for outdoor applications.

\section{Methodology}

2.1. Fabrication of $L C$. Four standard samples were fabricate with a minimum required compressive strength of 17.2 MPa and flexural strength of 1.45 MPa based on standard lightweight concrete. The preparation of samples was carried out according to ASTM C170 and ASTM C99. The proportion varied in WLA percentages which are equivalent to weight of cement (wt/wt) by using 1 to $3 \mathrm{~mm}$ particle sizes. The mixture proportions of basic ingredients, that is, Portland cement, water, and $10 \%$ superplasticizer, were the same as the lightweight cube concrete samples. Table 1 and Figure 1 show the quantities of four standard samples (a), (b), (c), and (d) for concrete cubic meter.

The LC for cube test samples was cast into the cube mould with dimension of $100 \mathrm{~mm}$ in length, $100 \mathrm{~mm}$ in width, and $100 \mathrm{~mm}$ in depth and left to cure at room temperature for 3 days while the LC mixture was poured in the fiberglass mould with dimensions of $420 \mathrm{~mm}$ in length, $332 \mathrm{~mm}$ in width, and $12.5 \mathrm{~mm}$ in depth and cured at room temperature for about 24 hours.

2.2. Preparation of TOP as Surface Coating. Monomer based on waste cooking oil and its composites were prepared [3-5] by mixing with cross-linking agent and doped with different percentages of superhydrophilic photocatalysis fillers of $\mathrm{TiO}_{2}$ named as TOP which were $1.0 \%, 1.5 \%, 2.0 \%$, and $2.5 \%$ equivalent to weight of monomer as shown in Table 2. The hand lay-up technique was used to coat the LC surfaces with TOP.
TABLE 1: Proportions ratio of LC samples preparation with WLA.

\begin{tabular}{lcccc}
\hline \multirow{2}{*}{ Materials } & \multicolumn{4}{c}{ Proportions } \\
& $\mathrm{a}(\mathrm{wt} / \mathrm{wt})$ & $\mathrm{b}(\mathrm{wt} / \mathrm{wt})$ & $\mathrm{c}(\mathrm{wt} / \mathrm{wt})$ & $\mathrm{d}(\mathrm{wt} / \mathrm{wt})$ \\
\hline Portland cement & 1 & 1 & 1 & 1 \\
Water & 0.5 & 0.5 & 0.5 & 0.5 \\
WLA (1-3 mm) & 0.55 & 0.60 & 0.65 & 0.70 \\
\hline
\end{tabular}

TABLE 2: Fabrication of LC coated with TOP for all test specimens.

\begin{tabular}{|c|c|c|c|}
\hline No & Samples & LC surface coating treatment & $\begin{array}{l}\text { TOP Thickness } \\
(\mathrm{mm})\end{array}$ \\
\hline 1 & $\mathrm{~A}$ & Uncoated surface & 0 \\
\hline 2 & B & $\begin{array}{l}\text { Surface coated with neat } \\
\text { biopolymer }\end{array}$ & 0.30 \\
\hline 3 & $\mathrm{C}$ & $\begin{array}{l}\text { Surface coated with TOP } \\
\left(1.0 \% \mathrm{TiO}_{2} \mathrm{wt} / \mathrm{wt} \text { of }\right. \\
\text { biomonomer })\end{array}$ & 0.30 \\
\hline 4 & $\mathrm{D}$ & $\begin{array}{l}\text { Surface coated with TOP } \\
\left(1.5 \% \mathrm{TiO}_{2} \mathrm{wt} / \mathrm{wt} \text { of }\right. \\
\text { biomonomer })\end{array}$ & 0.30 \\
\hline 5 & $\mathrm{E}$ & $\begin{array}{l}\text { Surface coated with TOP } \\
\left(2.0 \% \mathrm{TiO}_{2} \text { wt/wt of }\right. \\
\text { biomonomer })\end{array}$ & 0.30 \\
\hline 6 & $\mathrm{~F}$ & $\begin{array}{l}\text { Surface coated with TOP } \\
\left(2.5 \% \mathrm{TiO}_{2} \mathrm{wt} / \mathrm{wt} \text { of }\right. \\
\text { biomonomer })\end{array}$ & 0.30 \\
\hline
\end{tabular}

2.3. Compressive Strength Test for LC. The compressive strength test for LC and standard samples (a), (b), (c), and (d) was conducted after 7 days of standard curing. A compressive test machine $2000 \mathrm{kN}$ fully automatic, KalTest model no: QTC 2000, was used to determine the maximum compressive loads carried by various cubes. The load was applied at a rate of $15 \mathrm{~N} / \mathrm{mm}^{2}$ per minute in accordance with ASTM C170 test method [10].

2.4. Flexural Strength Test for LC. The flexural strengths of LC and standard concrete specimens were determined after 7 days of standard curing. The beams were tested in the laboratory using Universal Testing Machine $1000 \mathrm{kN}$. The load was applied at a rate of $0.16 \mathrm{~N} / \mathrm{mm}^{2}$ per second in accordance with the ASTM C99 test method. In the test, a load is applied through two rollers at the third points of the span until specimen breaks. Under these conditions, the lower surface of the beam is in tension. The beam fails by the growth of a crack from the tensile zone through the concrete. Using standard beam formula by (1), the failure stress can be calculated from dimension and load at the fracture [11]:

$$
\sigma=\frac{3 F L}{\left[2 b d^{2}\right]}
$$

where $F=$ load (force) at the fracture $(\mathrm{N}), L=$ length of the support system $(\mathrm{mm}), B=$ width of sample $(\mathrm{mm}), D=$ thickness of sample $(\mathrm{mm}), \Sigma=$ failure stress $(\mathrm{MPa}), \mathrm{Mc}=$ weight of standard concrete roof tile, and $m_{\mathrm{LRT}}=$ weight of the lightweight roof tile by WLA. 


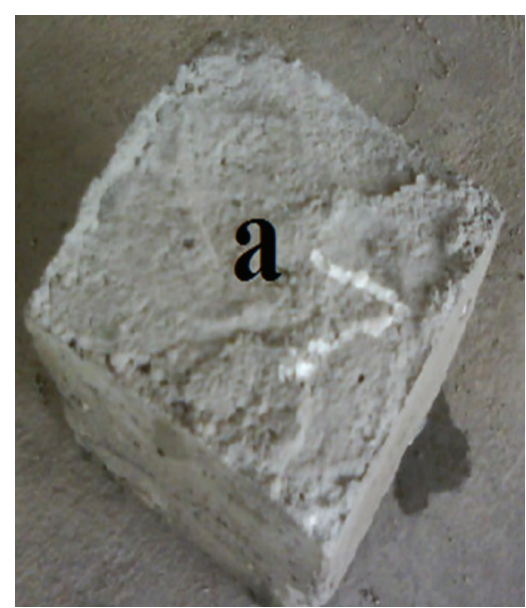

(a)

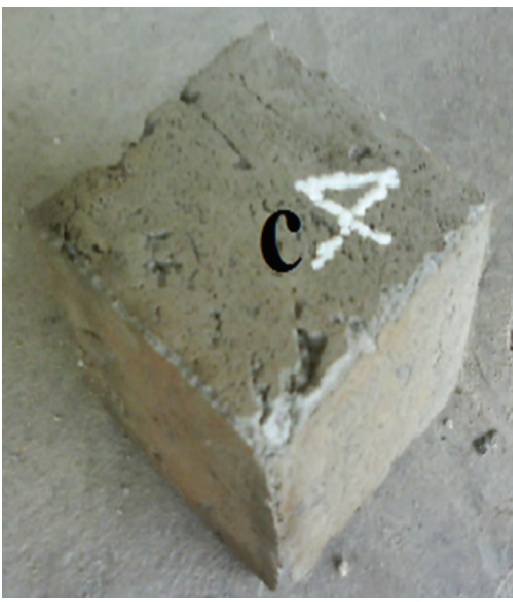

(c)

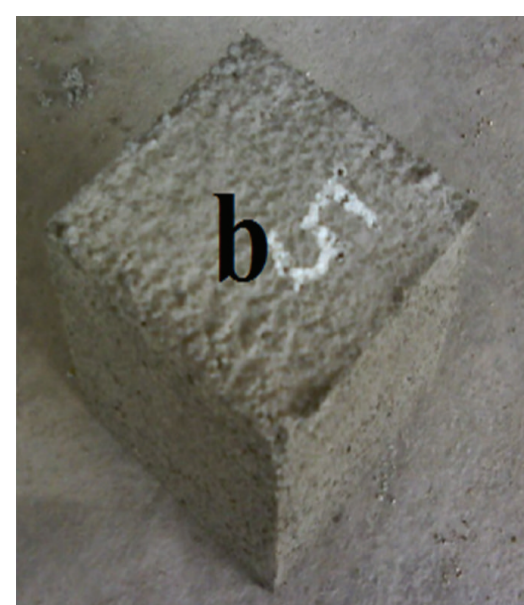

(b)

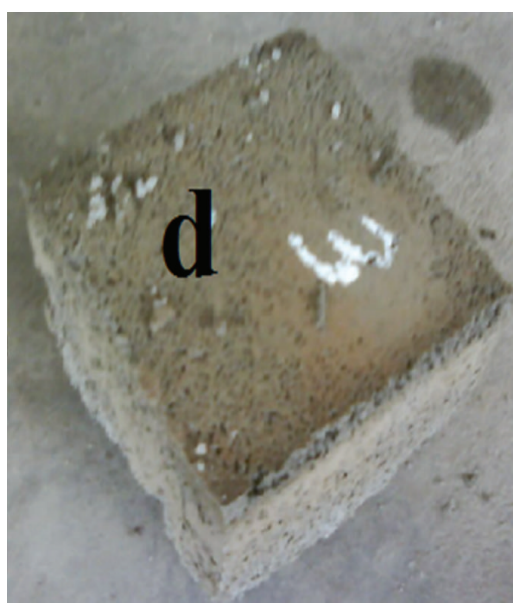

(d)

FigURE 1: Samples of LC for cube test with different WLA proportion ratio: (a) 0.55 , (b) 0.60 , (c) 0.65 , and (d) $0.70 \mathrm{wt} / \mathrm{wt}$.

2.5. Weight Reduction of LC. The percentage weight of LC was compared with standard concrete as determined by (2). The reduction of weight percentage was calculated as

$$
\text { \%weight }=\frac{\left(m_{c}-m_{\mathrm{LC}}\right)}{m_{c}} \times 100 .
$$

The percentage of weight reduction was taken from the average of three samples.

\subsection{Sunlight and Overnight Humidity Exposure of TOP Surface} Coating. This specification designates surface to be used as panels in weathering tests of coatings such as exterior solventborne or water-borne paints and other materials that are exposed to the sunlight and daily humidity. Referring to Figure 2, six categories of samples ((A), (B), (C), (D), (E), and $(\mathrm{F})$ ) with and without coating were exposed to sunlight and overnight humidity for eight weeks as shown in Figure 3 in accordance to ASTM D4258-05 [12]. This is to observe the self-clean properties of TOP indicated by colour change, sunburn, crack growth, dirt, oily deposition, and surface roughness.
2.7. TOP Surface Coating of Exposed and Unexposed to Outdoor, Sunlight, and Overnight Humidity by SEM. SEM has been used to analyze image of TOP before and after exposure to determine their surface before and after exposure to sunlight and humidity with different percentage of superhydrophilic fillers.

2.8. Scratch Resistance of TOP Surface by Pencil Test. Pencil hardness measurements have been used by the coating industry to determine the hardness of clear and pigmented organic coating films according to ASTM D3363 standard. The pencil consists of seventeen, ranging from $8 \mathrm{H}$ to $6 \mathrm{~B}$. The TOP surface coating with different percentages of photocatalysis superhydrophilic fillers was placed on a firm horizontal surface. The pencil was held firmly against $45^{\circ}$ angle and pushed away in a smooth stroke with uniform pressure. The process was started with the hardest pencil and continued down the scale of hardness until the pencil used did not gouge or scratch the film [13].

2.9. Water Droplet Test of TOP Surface Coating. Water droplets come in contact with a superhydrophobic surface with 


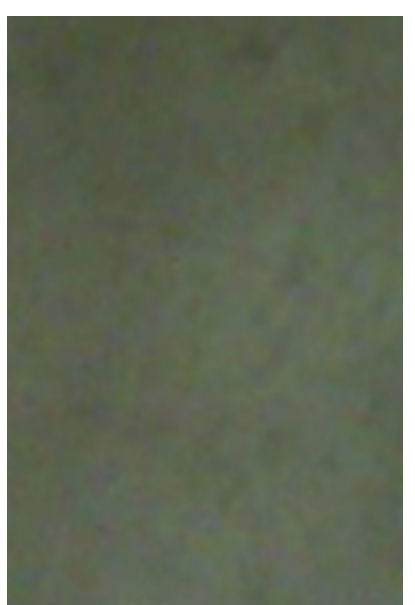

(A)

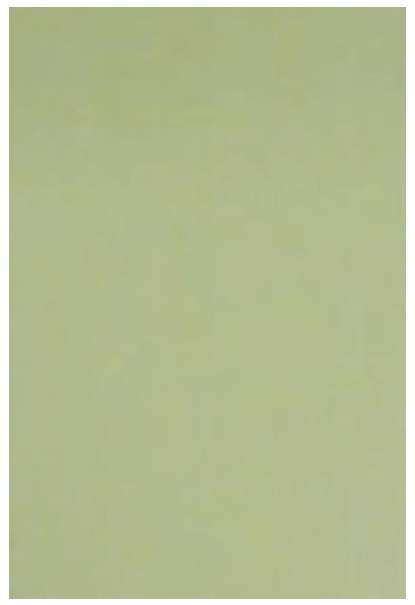

(D)

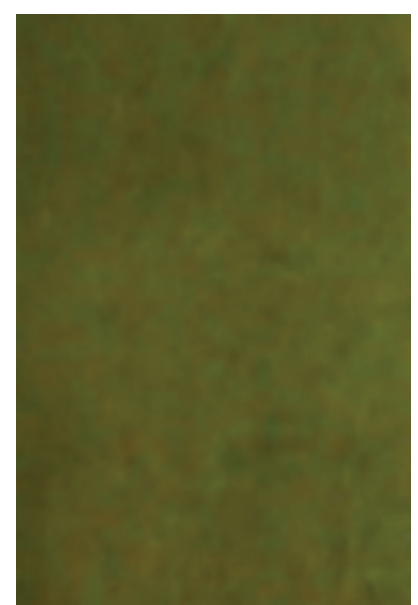

(B)

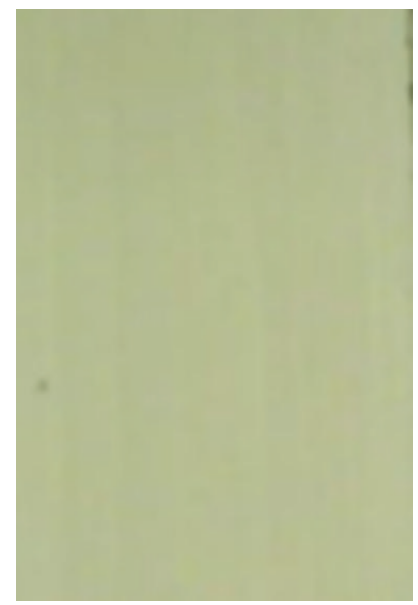

(E)

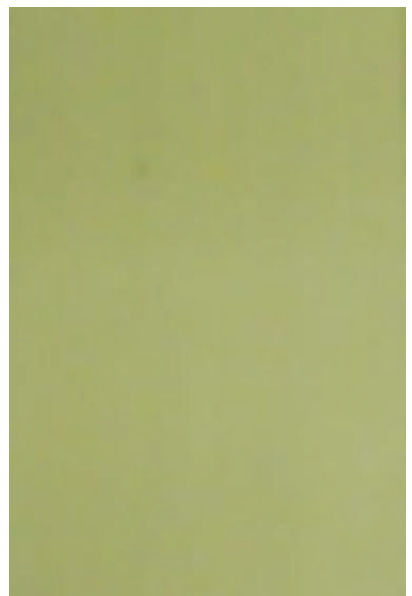

(C)

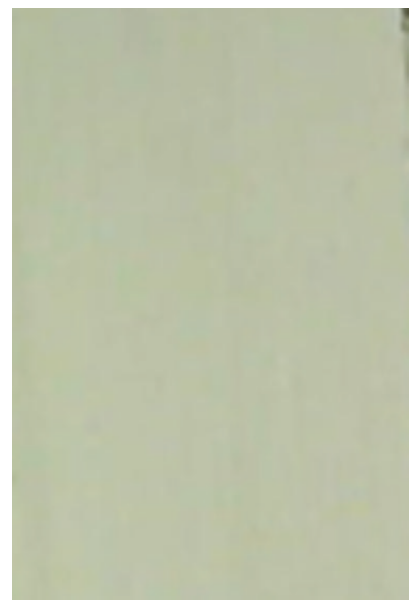

(F)

FIgURE 2: Samples of LC coated with TOP for outdoor exposure test.

contact angle higher than $150^{\circ}$ to form nearly spherical beads. The contaminants, either inorganic or organic, on such surfaces are picked up by water droplets or adhered to the water droplet and are removed from the surface when the water droplets roll off. The combination of low surface energy microstructured features which certainly reduce the contact area between the surface and water droplets will form superhydrophobic surfaces [14].

\section{Results and Discussion}

3.1. Compressive Strength Test of LC. The compressive strength test was conducted to measure the effect of different percentages of WLA loading in the LC. A systematic reduction in compressive strength with the increase in WLA loading for the $\mathrm{LC}$ was revealed. The cube concrete of compressive strength test for 7 days immersion with 55\% WLA (sample (C)) is $19.35 \mathrm{MPa}$ was achieved the value of standard composition concrete which is $17.20 \mathrm{MPa}$. Meanwhile, LC compressive strength with 60\% WLA loading (sample (B)), 65\% WLA loading (sample (C)), and 70\% WLA loading (sample (D)) are 16.95 $\mathrm{MPa}, 15.88 \mathrm{MPa}$, and 13.99 $\mathrm{MPa}$, respectively, as shown in Table 3 and Figure 4.
The integrity of the bond between these particle sizes of rubber aggregate and cement paste is critical. If there is no bond, the aggregate effectively represent of weakness compressive strength of the lightweight concrete design mixture [15]. Large-sized coarse aggregates are increasingly used in compressive strength in lightweight concrete for economic and environmental reasons due the large coarse aggregates also require less energy for size reduction with increased production rates [16].

The possible reason for reduction in strength with the inclusion of rubber in concrete mixtures is due to, first, the rubber particles are much softer or elasticity deformable than the surrounding cement paste, on loading cracks are initiated quickly around the rubber particle in the mix, which accelerated the failure of the rubber cement matrix. Secondly, due to the lack of adhesion between rubber particles and the paste, soft rubber particles may be viewed as voids in the concrete matrix. The assumed increase in void content would certainly cause a reduction in strength. The third possible reason for the strength reduction is the fact that rubberized mixture is dependent greatly on the coarse aggregate, density, and size because the aggregates are partially replaced by rubber and the reduction of strength is anticipated [17]. 
TABLE 3: Compressive strength of standard and LC concrete with different ratio of WLA to cement (wt/wt).

\begin{tabular}{|c|c|c|c|c|}
\hline Types of composite & Composite percentages (wt/wt) & Samples & Average compressive strength (MPa) & Density $\left(\mathrm{kg} / \mathrm{m}^{3}\right)$ \\
\hline \multirow{4}{*}{ Lightweight } & \multirow{4}{*}{$\begin{array}{ll} & 55 \% \\
\text { WLA } & 60 \% \\
& 65 \% \\
& 70 \%\end{array}$} & $\mathrm{~A}$ & 19.35 & 1750 \\
\hline & & $\mathrm{B}$ & 16.95 & 1683 \\
\hline & & $\mathrm{C}$ & 15.88 & 1580 \\
\hline & & $\mathrm{D}$ & 13.99 & 1468 \\
\hline Standard composition & Commercial $[\varepsilon$ & & 17.20 & 1900 \\
\hline
\end{tabular}

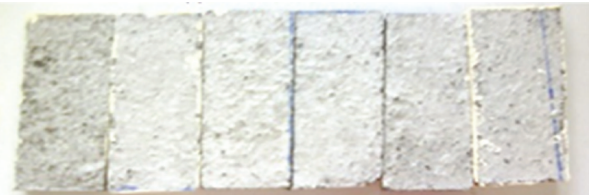

(a)

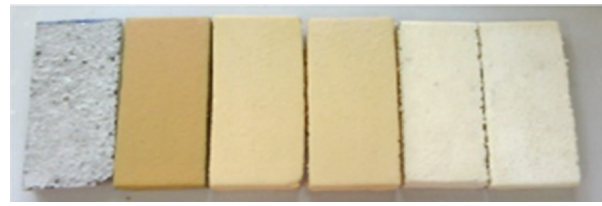

(b)

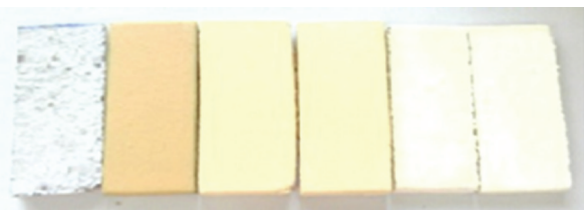

(c)

Figure 3: Samples of LC of (a) uncoated surface, (b) before being exposed to outdoor (sunlight and overnight humidity), and (c) after being exposed to outdoor (sunlight and overnight humidity).

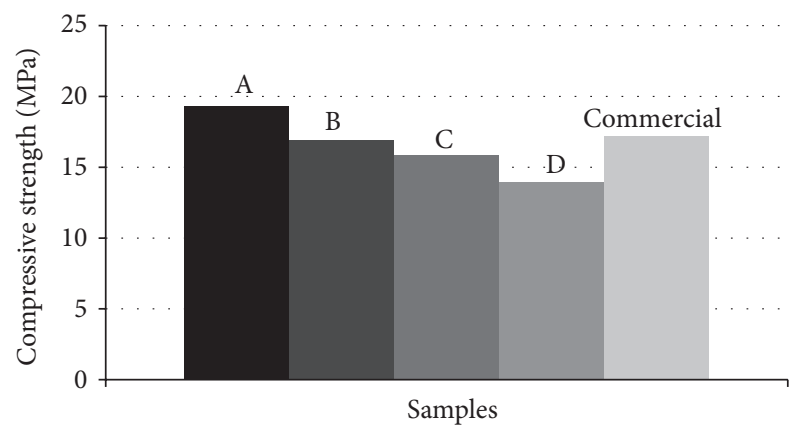

Figure 4: Compressive strength of standard lightweight cube concrete and LC with different ratio of WLA to cement (wt/wt) (A) 55\%, (B) $60 \%$, (C) $65 \%$, and (D) $70 \%$.

3.2. Flexural Strength Test of LC. The flexural strength behaviour of the mixtures is as shown in Table 4 . Figure 5 shows the load-deflection curves for four groups of samples; the deflection was obtained by deducting the effect of the support deformation. The relationship between the load and longitudinal tensile strain (on the lowest surfaces of the beam) is shown in Figure 6.

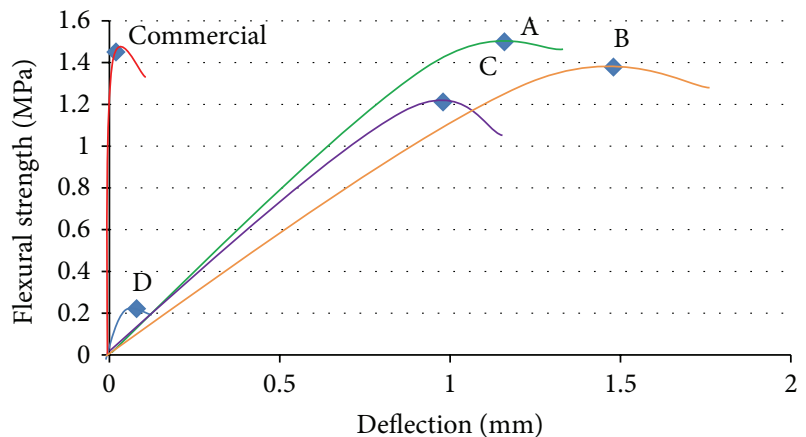

Figure 5: Flexural load against deflection of standard and lightweight cube concrete with different ratio of WLA to cement (wt/wt): (A) $55 \%$, (B) $60 \%$, (C) $65 \%$, and (D) $70 \%$.

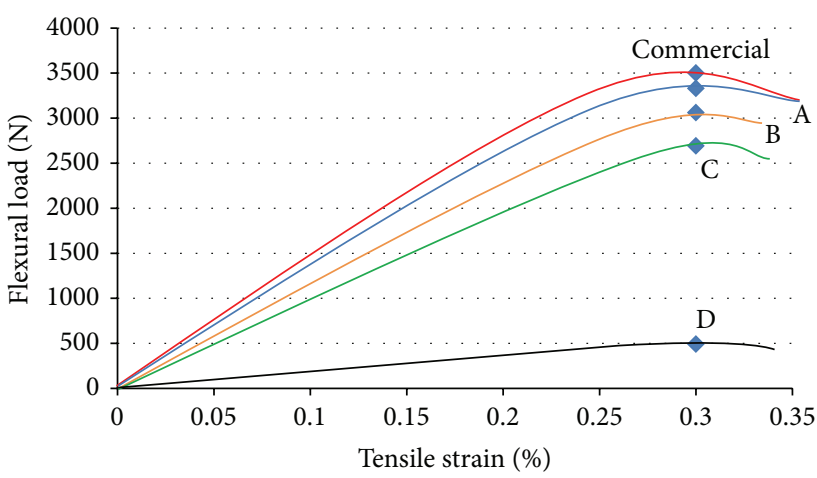

Figure 6: Flexural load against tensile strain of lightweight cube concrete with different ratio of WLA to cement (wt/wt): (A) $55 \%$, (B) $60 \%$, (C) $65 \%$, and (D) $70 \%$.

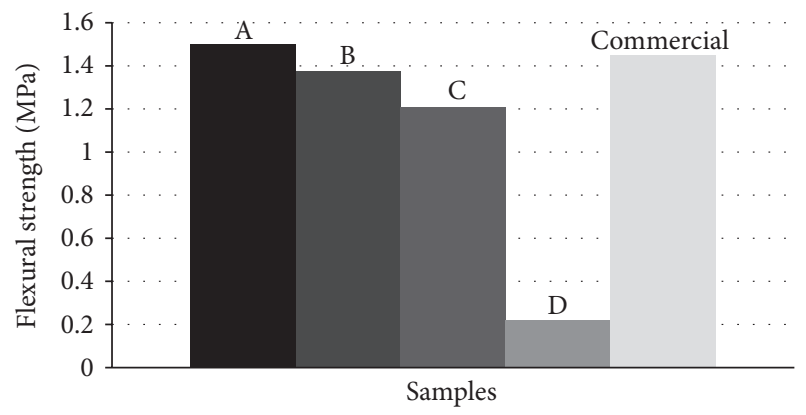

FIgURE 7: Flexural strength of lightweight cube concrete with different ratio of WLA to cement (wt/wt): (A) $55 \%$, (B) $60 \%$, (C) $65 \%$, and (D) $70 \%$. 

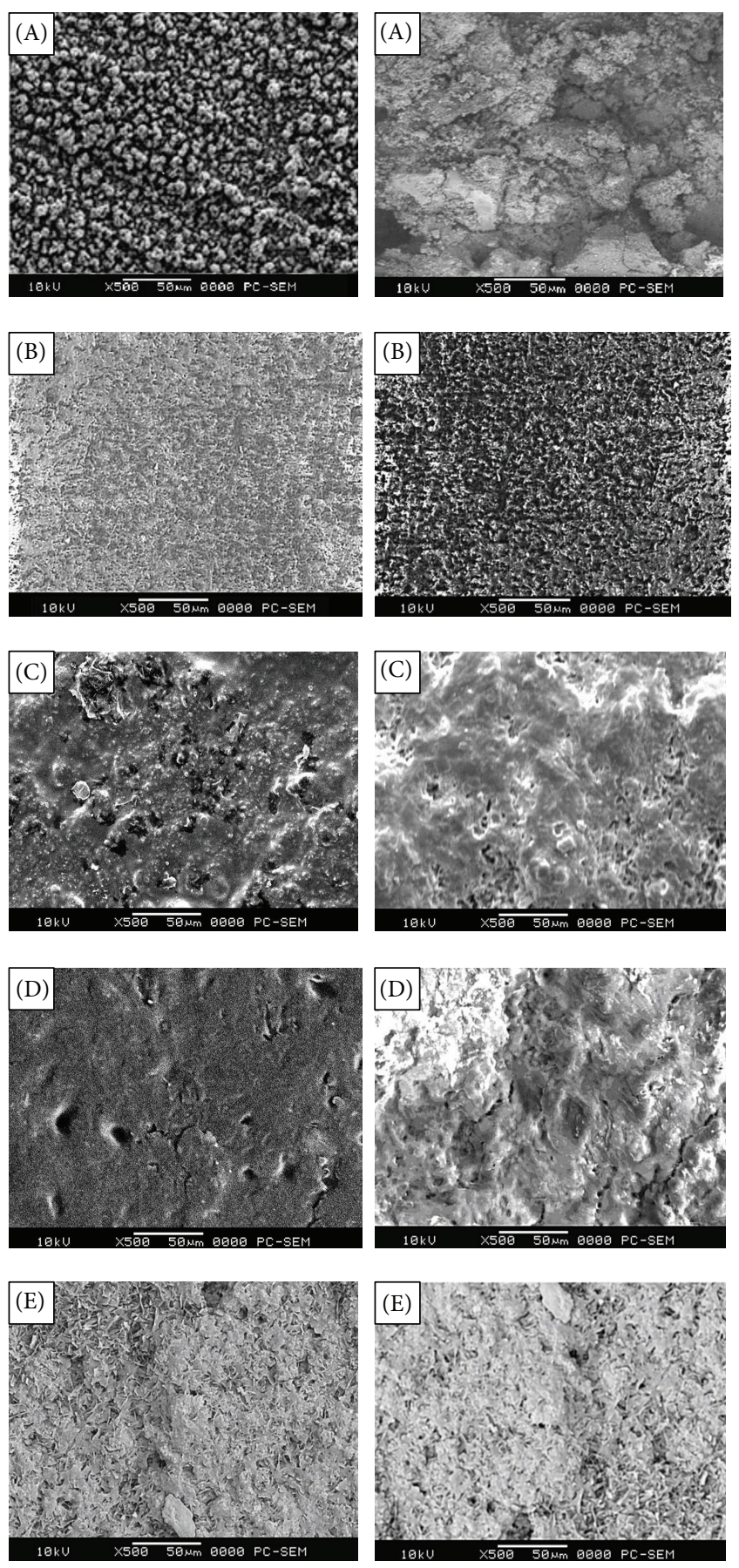

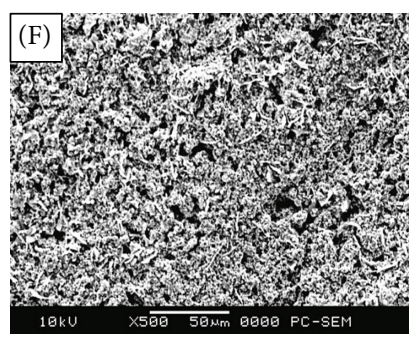

(a)
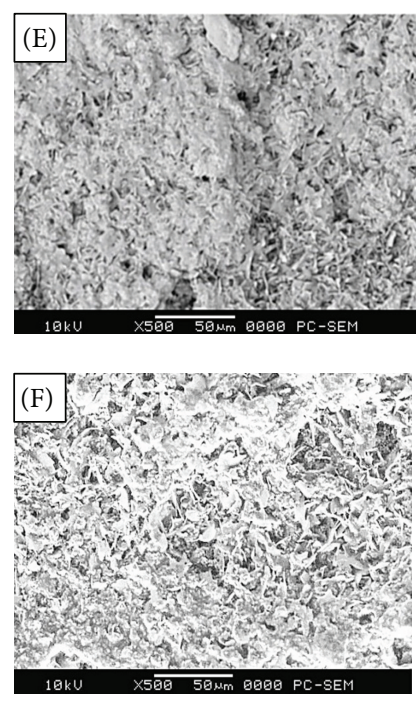

(b)
FIGURE 8: SEM morphology of LC coated with TOP for (a) being exposed and (b) after being exposed to sunlight and night humidity for samples (A), (B), (C), (D), (E), and (F).

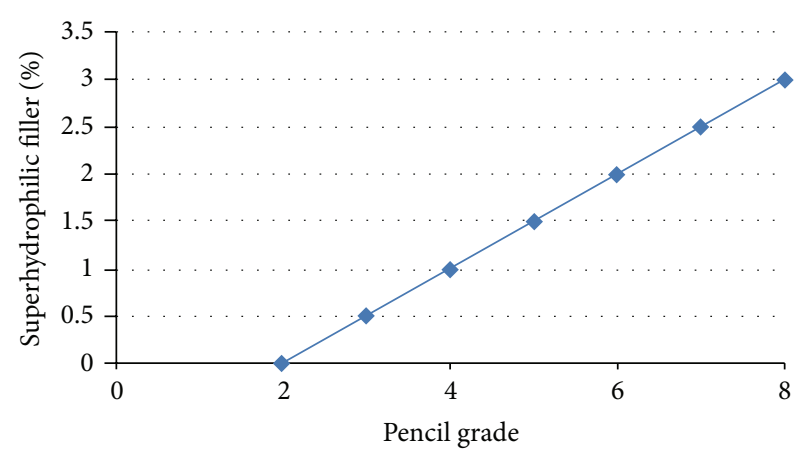

FIGURE 9: Influence of $\mathrm{TiO}_{2}$ superhydrophilic photocatalysis filler percentages against pencil grade that can gouge the TOP surfaces.

The flexural strength with minimum loading of $55 \%$ WLA concrete can sustain equivalent to the compressive strength behaviour of the standard concrete as refered to Table 3 and Table 4 . Referring to Figure 7, the failure of $55 \%, 60 \%$, and $65 \%$ of WLA loading for LC under flexural strength exhibited a ductile mode as compared to 70\% WLA loading (sample (D)) in concrete. The WLA concrete specimens could withstand larger deflection, indicating that they could absorb more energy than the standard concrete. This is largely due to the ability of WLA to undergo a large deformation before failure [18].

The flexural load versus tensile strain curves as shown in Figure 6 indicate that the WLA concrete can undergo a much higher tensile strain before failure as compared to the standard concrete as refered to Table 4. WLA plays an important role in enhancing the strength of the lightweight concrete. When cracks occur, due to the strain capacity being exceeded, they propagate along the vertical direction. When a crack reached the WLA particles, due to the elastic properties, the WLA particles would elongate, while carrying a portion of load, until the bond between the WLA and the cement paste was broken [19].

3.3. Weight Reduction of LC. Lightweight composite (LC) was successfully being reduced in weight which offers $35 \%$ lighter than the commercial concrete as indicated in Table 5 according to (2). The reduction in weight of lightweight concrete was adequate while improvement and maintaining was successfully achieved its mechanical strength as shown in the above experimental results.

Physical properties including unit weight and consistency of rubberized concretes are measured and compared. The unit weight was calculated as summation of the weights of the different mixes. It was noticed that the unit weight of the concrete mixes containing rubber decreases with increasing of the percentages of rubber particles contents [20].

3.4. Visual and SEM Morphology of Sunlight and Daily Humidity Exposure of LC Surface Coating of TOP. The result was recorded in several categories such as colour change, sunburn, crack, dirt, oily deposition, and surface roughness as tabulated in Table 6 . 


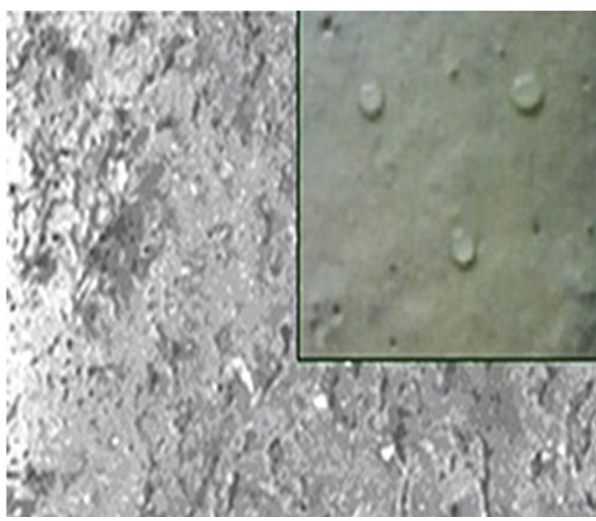

(a)

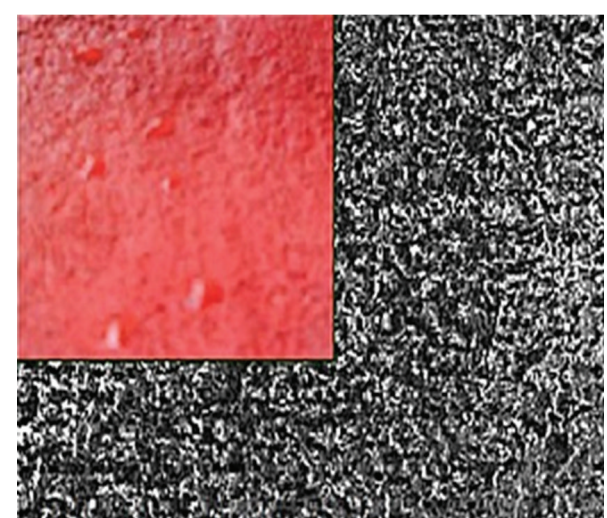

(b)

FIGURE 10: Water droplet test of LC, (a) with TOP of superhydrophobic and (b) without TOP of superhydrophobic property.

TABLE 4: Flexural strength and density of standard and lightweight cube concrete with different ratio of WLA to cement (wt/wt).

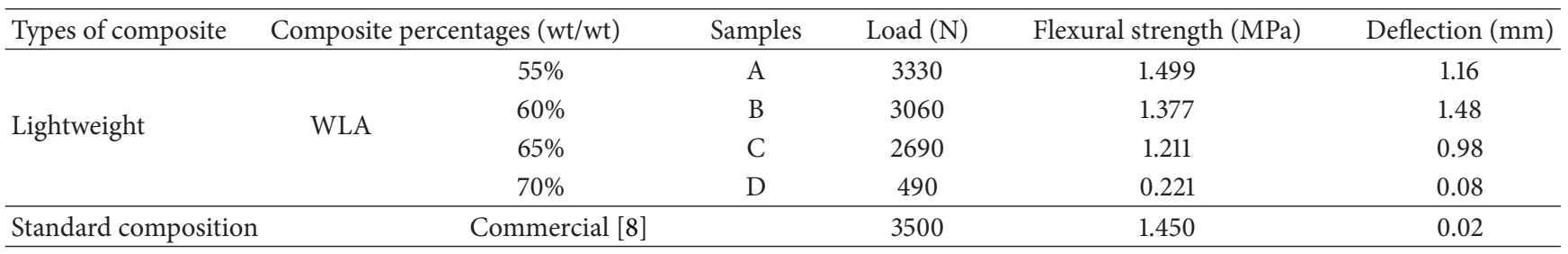

TABLE 5: Weight average of LC and standard commercial cube concrete.

\begin{tabular}{lccc}
\hline Types of composite & Sample & Weight $(\mathrm{kg})$ & Average weight $(\mathrm{kg})$ \\
\hline \multirow{4}{*}{ LC } & Sample 1 & 2.96 & \\
& Sample 2 & 3.03 & 3.03 \\
& Sample 3 & 3.11 & \\
\hline Standard concrete & \multicolumn{2}{c}{ Commercial [8] } & 4.30 \\
\hline
\end{tabular}

The observation of the physical properties was analyzed into two categories which are before and after exposure to sunlight and overnight humidity. As shown in Figure 3(b), for unexposed surface there are no physical changes observed such as color change, sunburn, crack, dirt, oily deposition, and surface roughness in room temperature for uncoated and coated surfaces. Meanwhile for exposed surfaces Figure 3(c) shows that the colours for sample (A) and (B) are dark brown upon exposure to sunlight and overnight humidity but did not show any crack, sunburn, dirt, oily deposition, or increase in surface roughness. Light brown colour for sample (C) was observed and no changes of colour for sample (E) and sample (F) can be observed. All the samples did not show any crack, sunburn, dirt, and oily deposition except surface roughness for sample (C), (D), (E), and (F); the surface roughness becomes smooth.

Through this observation, it is evident that the different percentages loading of TOP can affect the surface coating performance which can help to protect the changes of colour from deterioration upon environmental exposure especially with harsh equatorial conditions. Referring to Figure 3(c), it is revealed that for, sample $(\mathrm{F})$, coated surface with biopolymer doped with only $2.5 \%$ superhydrophilic particles stabilized the surface property of strong equatorial sunlight such as sunburn, crack, dirt, oily deposition, and surface roughness for longer period of time. This is due to the TOP as surface coating has the unique property of attracting rather than repelling water. The water lies flat on the surface and retained for approximately two days [21]. Furthermore, UV illumination of superhydrophilic filler leads to the formation of powerful agents with the ability to oxidize and decompose many types of bacteria and organic and inorganic materials. Hence, improvement of the quality property for surface finishing for outdoor application was observed. Longer period of exposure time should be proposed to further analyze the actual effect of surface properties as mentioned above [22].

The samples of LC with and without TOP were exposed to sunlight and overnight humidity for eight weeks. The result from SEM images was analyzed that dirt, bacteria, organic, and inorganic and other staining materials can easily be swept away with a stream of water.

As shown in Figure 8, sample (A), after being exposed to sunlight and overnight humidity, the surfaces become rough as grain raises, and the LC surface grows onto large crack; grain may loosen, loses its surface coherence, and becomes splinter, and fragments come off. All these effects brought about by a combination of light, water, mechanical forces, and heat.

The SEM micrograph of the LC surfaces before and after being exposed to sunlight and humidity exhibits that coated 
TABLE 6: Observation on uncoated and coated LC samples before and after exposure to sunlight and overnight humidity.

\begin{tabular}{lcccc}
\hline Sample & Observation & Color change & Sunburn, crack, dirt, oily deposition & Surface roughness \\
\hline \multirow{2}{*}{ A } & Before & Cream & No & Rough \\
& After & Dark brown & Yes & Rough \\
\hline B & Before & Cream & No & Low \\
& After & Dark brown & No & Low \\
C & Before & Cream & No & Low \\
& After & Light brown & No & Low \\
D & Before & Cream & No & Low/smooth \\
\hline E & After & Cream & No & Low \\
& Before & Light cream & No & Smooth \\
F & After & Light cream & No & Low \\
& Before & Lighter cream & No & Smooth \\
\hline
\end{tabular}

with renewable biopolymer based on waste cooking oil doped with superhydrophilic fillers (TOP) up to $2.5 \%$ shows the ability of coating to wash the surface dirt or other bacteria is high. It is also revealed that the coated surfaces with TOP have found to retain the original surface structure upon exposed to sunlight and humidity in a long term as compared to the sample (A) without coating. Therefore, no cracks, no sunburn, no dirt, and no oily deposition were found on the surfaces of coated sample after exposure.

3.5. Scratch Resistance Test. The pencil grade ranging from $2 \mathrm{H}$ to $8 \mathrm{H}$ can gouge or scratch the coated surface of biopolymer doped with different percentages of superhydrophilic fillers as shown in Figure 9. The higher the doped percentage of superhydrophilic as reinforcing fillers is, the higher the hardness of the pencil that can gouge or scratch the LC coated with TOP. This is due to the fact that the scratch resistance of the sample referred to the hardest pencil that will not gouge out the film. In general observation the coated sample with higher percentage of superhydrophilic has the optimum property of the scratch resistance while the uncoated sample shows the lowest value of scratch resistance by pencil test.

3.6. Water Droplet Test. Figure 10 shows the self-cleaning properties of TOP surfaces. The surfaces with superhydrophilic show that the self-cleaning mechanism has successfully been developed into TOP surfaces. The leaf of a lotus-plant has a water repellent wax cover which makes rain droplets just fall off the surface without spreading [23]. This is applicable or the main principal of the minimal contact between the TOP surfaces and the droplet of the water. This is due to the fact that the rain droplet that hits the TOP surfaces will immediately run off and on its way the droplet will catch dirt deposits from the surface, thus leaving the coated surface doped with $\mathrm{TiO}_{2}$ clean.

\section{Conclusion}

WLA with 55\% loading equivalent to weight of cement ratio (wt/wt) has the highest capability to sustain both compressive strength and flexural loads. It offered the weight reduction of $35 \%$ lighter than the commercial standard concrete roof tile. Considerable ductility of the WLA concrete can be observed when it is under compressive strength, especially under flexural loading. Such properties make it possible for these materials to be used in lightweight wall, pavement, floor, or road constructions where strength requirements are relatively low. Successful application of the material in these areas would be very promising. However, further investigation is needed before its practical application. For TOP as surface-coating results revealed different percentages loading of superhydrophilic filler that can be used to improve the material properties in practical use for outdoor application especially to enhance the stability of surface coating. The harsh equatorial environmental exposure test at certain period of time revealed that biopolymer from renewable resources doped with only $2.5 \%$ superhydrophilic shows no evidence of color or surface property changes such as sunburn, crack, dirt, oily deposition, and surface roughness. Therefore, by using TOP, it would benefit to improve the quality and stability of the surface finishing for outdoor and building application.

\section{Acknowledgments}

The authors would like to thank Universiti Tun Hussein Onn Malaysia (UTHM), Johor, and Malaysian Government for supporting this research under Malaysian Technical Universities Center of Excellent (MTUN-CoE), Vot C014.

\section{References}

[1] C. Limbachiya and J. Roberts, Construction Demolition Waste, Thoemas, London, UK, 1994.

[2] K. Singhai and K. Mehrotra, Environmental Issues and Management of Waste in Energy and Mineral Production, Taylor \& Francis, Rotterdam, The Netherlands, 2000.

[3] A. Z. M. Rus, "Degradation studies of polyurethanes based on vegetables oils. Part I. Photodegradatio," Progress in Reaction Kinetics and Mechanism, vol. 33, pp. 363-391, 2008. 
[4] A. Z. M. Rus, T. J. Kemp, and A. J. Clark, "Degradation studies of polyurethanes based on vegetable oils. Part 2. Thermal degradation and materials properties," Progress in Reaction Kinetics and Mechanism, vol. 34, no. 1, pp. 1-41, 2009.

[5] A. Z. M. Rus, "Polymers from renewable materials," Science Progress, vol. 93, no. 3, pp. 285-300, 2010.

[6] Z. Li, F. Li, and J. S. L. Li, "Properties of concrete incorporating rubber tyre particles," Magazine of Concrete Research, vol. 50, no. 4, pp. 297-304, 1998.

[7] S. Gintautas and G. Audrius, "Deformation properties of concrete with rubber waste additive," Material Science, vol. 13, no. 3, pp. 219-223, 2007.

[8] M. Anison, "An investigation into a hypothetical deformation and failure mechanism for concrete," Magazine of Concrete Research, vol. 6, no. 47, pp. 73-82, 1994.

[9] M. C. Bignozzi and F. Sandrolini, “Tyre rubber waste recycling in self-compacting concrete," Cement and Concrete Research, vol. 36, no. 4, pp. 735-739, 2006.

[10] B. D. Charles, ASTM C 170-90, Test Method for Compressive Strength of Dimension Stone, American Society for Testing and Materials, 2003.

[11] B. D. Charles, ASTM C 99, Modulus of Rupture of Dimension Stone, American Society for Testing and Materials, 2003.

[12] B. D. Charles, ASTM D4258-05, Standard Practice for Surface Cleaning Concrete for Coating, 2003.

[13] B. D. Charles, ASTM CD3363, Standard Test Method for Film Hardness by Pencil Test, American Society for Testing and Materials, 2000.

[14] A. Fujushima, K. Hishimoto, and T. Wanatabe, $\mathrm{TiO}_{2}$ Photocatalysis: Fundamentals and Applications, BKC, Tokyo, Japan, 1999.

[15] V. R. Scahaefer, "An Overview of Previous Concrete Applications in Stormwater Management and Pavement Systems," 2006, http://www.rmc-foundation.org/.

[16] P. D. Tennis, Portland Cement Characteristic. Portland Cement Association, 2004, http://www.concretetechnologytoday.org/.

[17] P. K. Mehta and P. J. M. Monteiro, Concrete, Properties and Materials, Prentice Hall, Englewood Cliffs, NJ, USA, 2nd edition, 1993.

[18] T. D. Biel and H. Lee, "Use of recycled tires in concrete, insfrastructure new materials and methods of repair," in Proceedings of the 3rd Materials Engineering Conference, pp. 351-358, San Diego, Calif, USA, November 1994.

[19] Z. K. Khatib and F. M. Bayomy, "Rubberized Portland cement concrete," Journal of Materials in Civil Engineering, vol. 11, no. 3, pp. 206-213, 1999.

[20] M. M. Balaha, "Effect of ground waste tite rubber as fine aggregate on the behaviour of concrete structures," ICI Jurnal, vol. 3, pp. 22-30, 2007.

[21] Danish, Use of Technical Textile Obtain Sustainable Selfcleaning Building Surface, 2006, http://www.nordforsk.org/.

[22] A. Papadopoulos, J. B. Rout, L. Guiillot et al., Innovative SelfCleaning and De-Polluting Façade Surfaces, Toronto, 2004.

[23] L. J. Calbo, Handbook of Coatings Additives, Marcel Dekker, New York, NY, USA, 1992. 

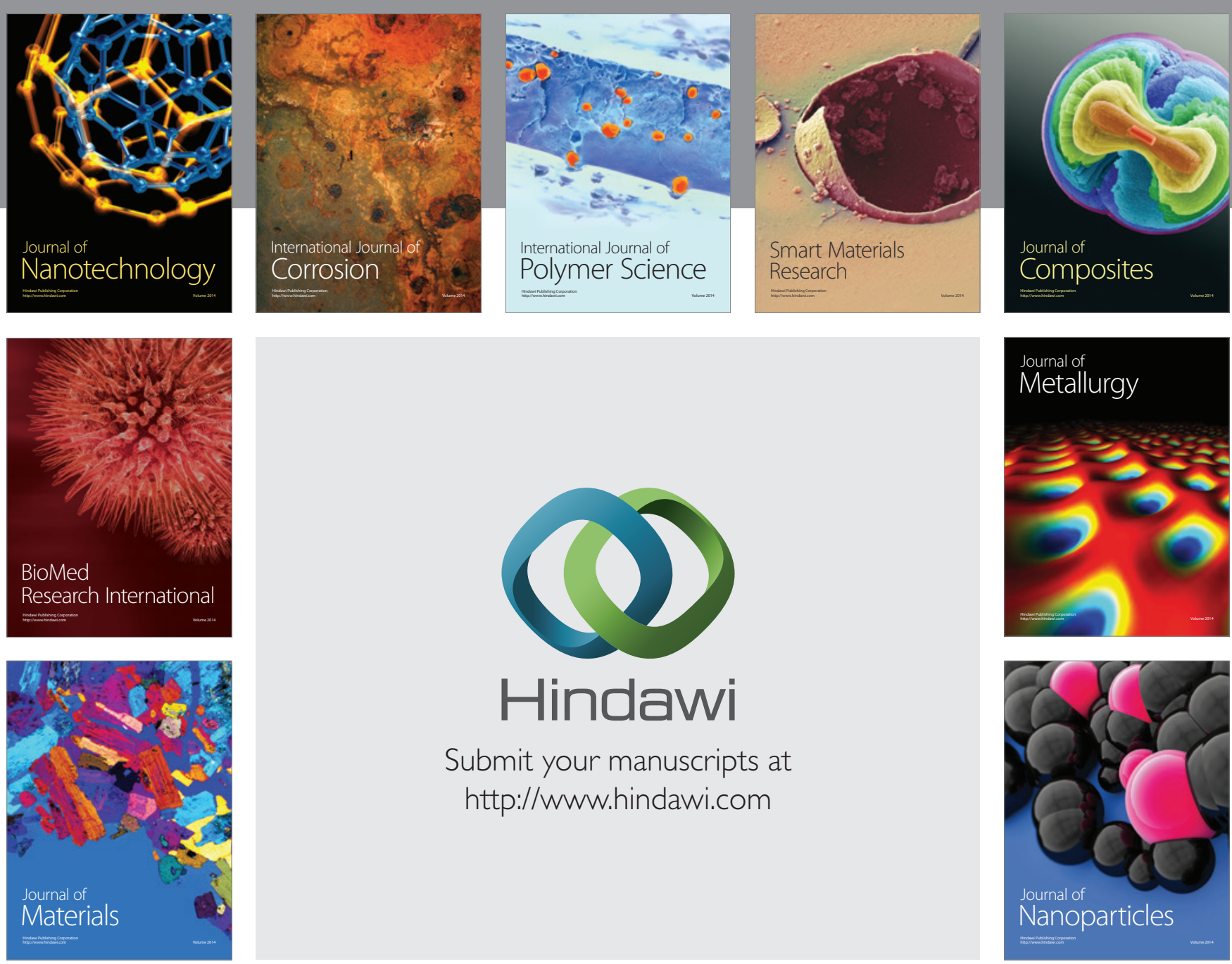

Submit your manuscripts at http://www.hindawi.com
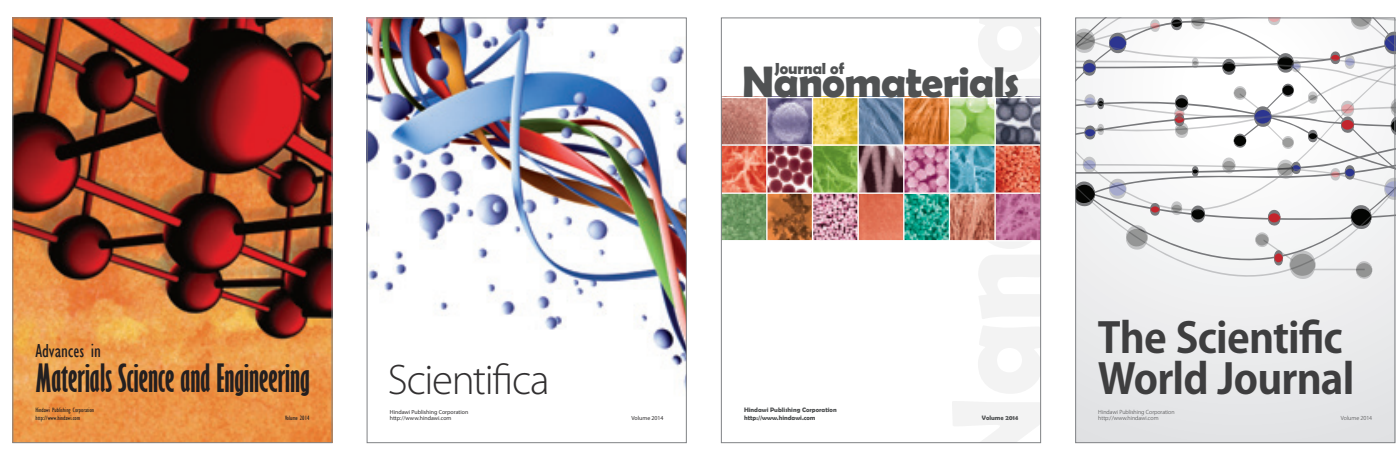

\section{The Scientific World Journal}
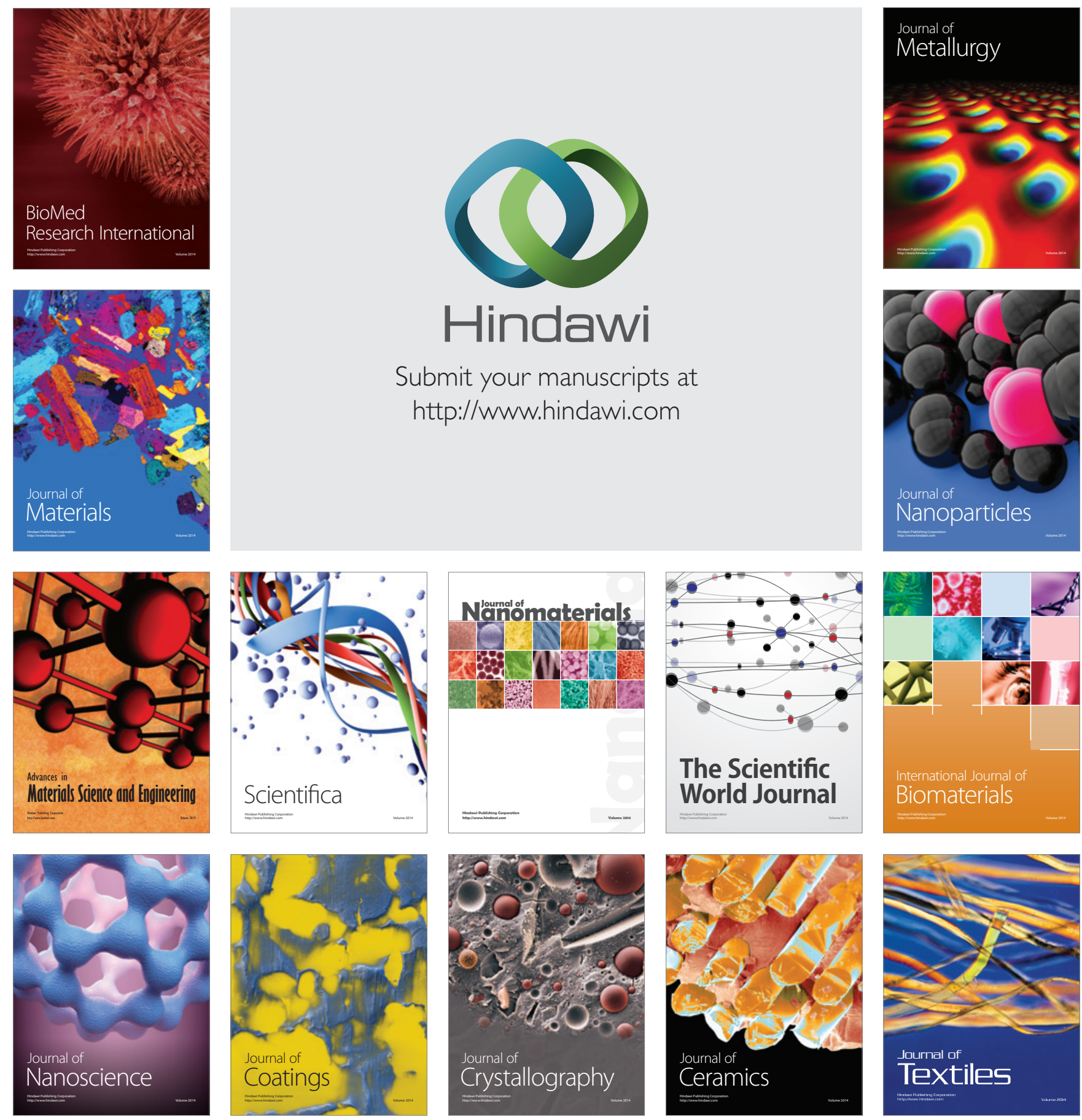